\title{
Qualidade seminal e histomorfometria dos órgãos reprodutivos de ovinos tratados com fluoreto de sódio
}

\author{
Seminal quality and reproductive histomorphometry of ram lambs treated with sodium fluoride
}

\author{
Andreane Filappi ${ }^{\mathrm{I} *}$ Danívia Prestes $^{\mathrm{I}}$ Ricardo Rocha $^{\mathrm{I}}$ Deila Rosely Schosller ${ }^{\mathrm{II}}$ Carlos Bondan ${ }^{\mathrm{II}}$ \\ José Francisco Bragança ${ }^{I V}$ Marcelo Cecim ${ }^{\mathrm{I}}$
}

\section{RESUMO}

O presente estudo objetivou avaliar as características espermáticas, os indicadores do metabolismo oxidativo do sêmen, o diâmetro dos túbulos seminíferos e a altura do epitélio testicular, do epididimário e do canal deferente de ovinos tratados com fluoreto de sódio. Foram utilizados 12 ovinos, com idade aproximada de cinco meses. Os animais foram divididos em grupo controle, o qual recebeu diariamente sal iodado (5g de $\mathrm{NaCl}$ animal ${ }^{-1}+0,2 \mathrm{mg} \mathrm{I}^{-1} \mathrm{~kg}^{-1}$ mária seca), e tratado, que recebeu sal iodado adicionado de fluoreto de sódio (4,7mg $F \mathrm{~kg}^{-1}$ de peso corporal). Aos 150 dias de tratamento, foram realizadas coletas de sêmen e, em seguida, os animais foram eutanasiados. Na comparação entre o grupo controle e o tratado, não foram observadas diferenças no percentual de motilidade, vivos : mortos e morfologia espermática, na concentração da glutationa reduzida seminal, no teor de zinco seminal, no peso testicular, na morfometria $e$ na histologia do testículo, na cauda do epidídimo e no canal deferente. A concentração de substâncias reativas ao ácido tiobarbitúrico (TBARs) e o teor de cobre no sêmen foram menores $(P<0,05)$ no grupo tratado. Conclui-se que a administração crônica de flúor para ovinos jovens não afeta a capacidade reprodutiva de uma forma geral. Entretanto, os dados sugerem que o flúor pode reduzir a lipoperoxidação e os teores de cobre que são essenciais para a capacitação espermática e a fertilização.

Palavras-chave: flúor, ovino, reprodução, histologia, TBARs, glutationa reduzida.

\section{ABSTRACT}

The objective of the present study was to evaluate different reproductive parameters of ram lambs treated with sodium fluoride. Spermogram, indicators of seminal oxidative profile, seminiferous tubules diameter and cell height of the testicular epithelium, epididimus and vas deferens were analyzed. Twelve 5-month-old ram lambs were used. They were allocated into one of two experimental groups: The control, which received daily iodized salt (5g NaCl animal $\left.{ }^{-1}+0.2 \mathrm{mg} \mathrm{I} \mathrm{kg}^{-1} \mathrm{DM}\right)$; and the treated, which received $\left(5 \mathrm{~g} \mathrm{NaCl}\right.$ animal ${ }^{-1}+0.2 \mathrm{mg} \mathrm{I} \mathrm{kg}^{-1}$ $\left.\mathrm{DM}+4.7 \mathrm{mg} \mathrm{F} \mathrm{kg}^{-1} \mathrm{BW}\right)$. After 150 days of treatment, animals went through a complete andrological exam, and were euthanized on the next day. No differences were observed in sperm motility, dead: alive ratio and morphology between the control and treated group. Also, seminal concentration of reduced glutathione and zinc, as well as, testicular weight, histology and morphometry of testicles, caudal portion of epididimus and vas deferens did not differ between groups. The seminal concentration of thiobarbituric acid reactive substances (TBARs) and seminal copper levels were lower $(P<0.05)$ in the treated group. We conclude that chronic fluoride administration to lambs does not affect reproductive capacity as a whole. However, the data suggest that fluoride can induce a reduction in seminal lipoperoxidation and copper levels with are essential for sperm capacitation and fertilization.

Key words: fluoride, sheep, reproduction, histology, TBARs, reduced glutathione.

\section{INTRODUÇÃO}

A intoxicação crônica de flúor (F) em ruminantes pode ser observada no caso de consumo contínuo de suplementos minerais contendo alto teor de F, consumo de água rica em F e pastejo em forragens

\footnotetext{
IDepartamento de Clínica de Grandes Animais, Universidade Federal de Santa Maria (UFSM), Campus Camobi, Santa Maria, RS, Brasil. 97105900. E-mail: afilappi@bol.com.br. *Autor para correspondência.

ID Departamento de Histologia, UFSM, Santa Maria, RS, Brasil.

IIIDepartamento de Medicina Veterinária, Universidade de Passo Fundo (UPF), Passo Fundo, RS, Brasil.

${ }^{\text {IV}}$ Departamento de Medicina Veterinária, Universidade do Oeste de Santa Catarina (UNOESC), Xanxerê, SC, Brasil.
} 
contaminadas com $\mathrm{F}$, adjacentes às indústrias (UNDERWOOD \& SUTTLE, 1999). Pesquisas têm sido realizadas a fim de avaliar os diferentes efeitos biológicos relacionados à exposição crônica ao $\mathrm{F}$, incluindo fluorose dental e fluorose esquelética (CHINOY \& SEQUEIRA, 1989). No entanto, os efeitos do F sobre a reprodução, acarretando redução da fertilidade, são conflitantes (LI et al., 1987; GHOSH et al., 2002).

A administração de $F$ resulta em sua absorção e em seu transporte, via corrente sangüínea, para os tecidos e órgãos, podendo causar mudanças estruturais e funcionais (CENESIZ et al., 2005). No sistema reprodutivo dos machos, é possível que a rota do $\mathrm{F}$ proveniente do sangue seja o citoplasma das células epiteliais e, posteriormente, o ejaculado (ZAKRZEWSKA et al., 2002). A permeabilidade da barreira testicular pode ser atravessada durante uma longa exposição ao F, causando danos espermatogênicos e resultando em interrupção da espermatogênese (SUSHEELA \& KUMAR, 1991).

Mudanças na qualidade espermática induzidas pelo $\mathrm{F}$ são descritas in vivo e in vitro em algumas espécies como rato, camundongo, coelho, cobaia e homem (WAN et al., 2006). Entretanto, os resultados experimentais são divergentes. Algumas descrições indicam que o $F$ não afeta a qualidade espermática de ratos (SPRANDO et al., 1997; COLLINS et al., 2001) e camundongos (DUNIPACE et al., 1989). Em outros experimentos, sugere-se que o $\mathrm{F}$ pode reduzir a qualidade espermática e a fertilidade (GHOSH et al., 2002; BATAINEH \& NUSIER, 2006; WAN et al., 2006; HUANG et al., 2007). Uma das hipóteses é que isso ocorra devido à intensificação da geração de radicais livres e da peroxidação lipídica e à alteração do sistema antioxidante, em decorrência dos efeitos tóxicos do F (PATEL \& CHINOY, 1998). Esta discrepância entre resultados ainda pode ser devido a diferenças entre as espécies utilizadas como modelo experimental e no tipo, na duração e na dosagem do tratamento (LI et al., 1987; DUNIPACE et al., 1989).

Em ovinos, quase todos os experimentos conduzidos para avaliar a ação do F sobre o sistema reprodutivo foram realizados in vitro (ZAKRZEWSKA et al., 2002). Nesse contexto, o presente estudo teve por objetivo avaliar as características espermáticas, os indicadores do metabolismo oxidativo do sêmen, o diâmetro dos túbulos seminíferos e a altura do epitélio testicular, do epididimário e do canal deferente de ovinos tratados com fluoreto de sódio.

\section{MATERIAL E MÉTODOS}

Foram utilizados 12 ovinos, machos, mestiços das raças Texel x Ile de France, com idade aproximada de cinco meses e peso vivo de 22 a $25 \mathrm{~kg}$. Os animais foram mantidos em baias com piso ripado e receberam como dieta base o equivalente a $3 \%$ do peso vivo de feno de alfafa e água ad libitum. Após o período de adaptação de 15 dias, os animais foram divididos em grupos: controle $(n=6)$ e tratado $(n=6)$. O primeiro grupo recebeu sal iodado ( $5 \mathrm{~g}$ de $\mathrm{NaCl}$ animal ${ }^{-1}+0,2 \mathrm{mg}$ I $\mathrm{kg}^{-1}$ matéria seca) e o segundo recebeu sal iodado adicionado de fluoreto de sódio $\left(4,7 \mathrm{mg} \mathrm{F} \mathrm{kg}^{-1}\right.$ de peso corporal). Os sais foram diluídos em água destilada e administrados por meio de sonda oro-esofágica, diariamente, por um período de 150 dias. A dose foi ajustada a cada 14 dias, de acordo com o peso dos ovinos. Quinzenalmente, os ovinos foram avaliados clinicamente quanto ao aspecto dentário para verificar possíveis alterações características de fluorose.

No final do período experimental, aos 150 dias de tratamento, foram realizadas duas coletas de sêmen, mediante eletroejaculação, com intervalo de oito horas. A primeira amostra de sêmen foi submetida à centrifugação para obtenção do plasma seminal para posterior análise de cobre $(\mathrm{Cu})$ e zinco $(\mathrm{Zn})$. Essas determinações foram realizadas por Espectrometria de Massa com Plasma Indutivamente Acoplado (ELAN ${ }^{\circledR}$ DRC II- PerkinElmer SCIEX, Concord, Canadá), de acordo com a técnica recomendada por EATON et al. (1995).

A segunda amostra de sêmen foi fracionada. Uma alíquota foi utilizada para avaliação das características seminais: motilidade progressiva, viabilidade (vivos : mortos) e morfologia espermática, conforme metodologias citadas por SILVA et al. (1993). A outra alíquota de sêmen foi acondicionada em nitrogênio líquido $\left(-196^{\circ} \mathrm{C}\right)$, imediatamente após a coleta, sem adição de diluidores ou crioprotetores, para posterior análise da lipoperoxidação e da concentração da glutationa reduzida (GS). A peroxidação lipídica foi determinada de acordo com o método de formação de espécies reativas ao ácido tiobarbitúrico (TBARs), quantificada a partir da metodologia descrita por OHKAWA et al. (1979). A determinação da concentração da GS, por meio dos grupamentos tióis não-protéicos (NPTH), baseou-se na redução do ditionitrobenzeno, conforme descrito por ELLMAN (1959). As análises bioquímicas foram realizadas por meio de espectrofotometria.

Ao final do experimento, os animais foram eutanasiados e partes do sistema reprodutivo foram removidas para posterior análise. Os testículos dos 
animais foram pesados e posteriormente o testículo, a cauda do epidídimo e o canal deferente direito de cada animal foram fixados em Solução de Bouin's para posterior exame histológico. As lâminas foram coradas com hematoxilina-eosina. A histomorfometria dos órgãos foi efetuada mediante análise do diâmetro dos túbulos seminíferos e da altura do epitélio seminífero, do epididimário e do canal deferente (MOURA et al., 2006). Este procedimento foi realizado com ocular micrométrica (Leica, Heildeberg, Alemanha) por meio de microscópio de luz. Consideraram-se para a medição 10 estruturas histológicas (com repetição), sendo que a leitura foi efetuada em cinco campos (aumento de 100x), totalizando 100 estruturas analisadas. Não foi considerado na análise o índice de retração linear.

Os dados foram expressos em média \pm desvio padrão. As diferenças entre os grupos controle e tratado foram analisadas pelo teste t de Student.

\section{RESULTADOS E DISCUSSÃO}

A dose de F utilizada neste experimento (4,7 $\mathrm{mg} \mathrm{F} \mathrm{kg}^{-1}$ de peso corporal) foi baseada em estudo prévio realizado por KESSABI et al. (1986) em ovinos, no qual foi capaz de produzir um quadro de fluorose (dental e esquelética) nos animais. No presente experimento, os ovinos tratados com F não apresentaram alterações passíveis de fluorose. Todos os animais apresentaram apetite normal, crescimento regular e bom estado corporal, atingindo condição de abate ao final do experimento.

$\mathrm{Na}$ avaliação seminal não foi observada diferença $(\mathrm{P}>0,05)$ no percentual de espermatozóides móveis, vivos e com defeitos entre os animais do grupo controle e do tratado. Aúnica anormalidade espermática observada, em ambos os grupos, foi cauda enrolada (Tabela 1). Esse defeito espermático pode ter ocorrido como um artefato de coleta, em conseqüência de um possível choque térmico (SILVA et al., 1993). Estudos em animais de laboratório demonstraram que o consumo de NaF na água de beber (5, 10 e 150ppm) diminui a qualidade espermática (CHINOY et al., 1995; CHINOY et al., 1997; PUSHPALATHA et al., 2005; WAN et al., 2006), bem como induz alterações histológicas no epitélio seminífero (WAN et al., 2006). Em um experimento in vitro com sêmen ovino de animais de produção, foi observado decréscimo na motilidade espermática após adição de diferentes concentrações de $\operatorname{NaF}\left(20,100,200 \mu \mathrm{mol} \mathrm{L} \mathrm{L}^{-1}\right.$ e $0,1 \mathrm{~mol} \mathrm{~L}^{-1}$ ) (ZAKRZEWSKA et al., 2002). Embora os efeitos negativos do F sobre a qualidade espermática sejam relatados, os resultados experimentais diferem. ORTIZPÉREZ et al. (2003), em estudo realizado para avaliar a
Tabela 1 - Média \pm desvio padrão da motilidade, de espermatozóides vivos, da morfologia espermática, da concentração de espécies reativas ao ácido tiobarbitúrico (TBARs), da glutationa reduzida (GS), do cobre e do zinco no sêmen de ovinos alimentados com sal iodado (controle) acrescido de fluoreto de sódio (4,7 $\mathrm{mg} \mathrm{F} \mathrm{kg}^{-1}$ de peso vivo, tratado) durante 150 dias.

\begin{tabular}{lcl}
\hline Parâmetro & Controle $(\mathrm{n}=6)$ & Tratado (n=6) \\
\hline Motilidade (\%) & $56,0 \pm 20,7$ & $51,7 \pm 26,4$ \\
Espermatozóides vivos (\%) & $65,4 \pm 28,5$ & $68,9 \pm 3,8$ \\
Defeito total (\%) & $11,6 \pm 8,2$ & $13,2 \pm 10,3$ \\
TBARs (nmol MDA ml $\left.{ }^{-1}\right)$ & $0,77 \pm 0,2$ & $0,37 \pm 0,1^{*}$ \\
GS (nmol L $\left.{ }^{-1} \mathrm{NPTH}\right)$ & $8,5 \pm 2,4$ & $7,7 \pm 0,8$ \\
Cobre $\left(\mu \mathrm{mol} \mathrm{L}^{-1}\right)$ & $12,5 \pm 9,4$ & $3,0 \pm 1,5^{* *}$ \\
Zinco $\left(\mu \mathrm{mol} \mathrm{L}{ }^{-1}\right)$ & $21,4 \pm 12,2$ & $14,6 \pm 8,9$ \\
\hline
\end{tabular}

* $\mathrm{P}<0,01 ; * * \mathrm{P}<0,05$.

qualidade seminal de homens consumindo diariamente alta (13,4 a 27,4mg F dia-1) e baixa dose de F (2-13mg F dia $^{-1}$ ), não observaram diferença na percentagem de motilidade, viabilidade e morfologia espermática entre os grupos, mantendo-se os parâmetros dentro da normalidade.

As concentrações de TBARs, GS, Cu e Zn encontradas no sêmen dos animais deste experimento estão expressas na tabela 1. A concentração de TBARs foi menor $(\mathrm{P}<0,01)$ no sêmen dos animais tratados com $\mathrm{NaF}$, indicando redução da peroxidação lipídica. KRECHNIAK \& INKIELEWICZ (2005), investigando a inter-relação entre a concentração de F e de radicais livres em diferentes sistemas, verificaram que, na maioria dos casos, há correlação positiva $(r=0,84)$ entre a concentração de $\mathrm{F}$ e de TBARs. As espécies reativas ao oxigênio (EROs) podem causar efeitos benéficos ou prejudiciais à função espermática, dependendo da natureza e de sua concentração. Em condições fisiológicas, os espermatozóides produzem pequenas quantidades de EROs necessárias à capacitação e à reação acrossômica (AGARWAL \& PRABAKARAN, 2005).

Em relação à concentração da GS no sêmen, não foi constatada diferença significativa $(\mathrm{P}>0,05)$ entre os grupos. Provavelmente, essa similaridade de resultados esteja relacionada à concentração de TBARs verificada. Uma vez que não houve incremento na peroxidação lipídica, também não houve necessidade de uma resposta adaptativa por parte da GS. Segundo CHLUBEK (2003), elevados teores de F podem inibir a geração de EROs. Esse fato pode justificar a baixa concentração de TBARs verificada, neste experimento, nos animais do grupo tratado. De acordo com a literatura, a dose de F que foi utilizada é considerada 
elevada para a espécie ovina (UNDERWOOD \& SUTTLE, 1999). BHANUPRAKASH (2004) não verificou alteração no sistema antioxidante e na peroxidação lipídica no sangue de homens com fluorose e animais intoxicados experimentalmente com F. Por outro lado, KALYANALAKSHMI et al. (2007) observaram incremento na lipoperoxidação e na redução do potencial do sistema antioxidante celular no sangue de ratos com fluorose. Nessa espécie, resultado similar foi verificado por SHIVARAJASHANKARA et al. (2001) no tecido testicular. Esta diferença entre resultados pode advir de alguns fatores como espécie animal utilizada, dose, forma e tempo de ingestão do F (RZEUSKI et al., 1998). De acordo com ZAYAS et al. (2000), em relação ao sistema reprodutivo, a determinação de indicadores do metabolismo oxidativo proporciona informação suplementar sobre a qualidade da espermatogênese, contribuindo para o diagnóstico de fertilidade. Nesse experimento, a avaliação do perfil oxidativo do plasma seminal talvez tenha sido o parâmetro mais sensível para detectar as alterações reprodutivas iniciais decorrentes da administração do F.

A concentração de Cu no sêmen foi menor $(\mathrm{P}<0,05)$ no grupo tratado que no controle, enquanto que a concentração de $Z n$ não diferiu $(P>0,05)$ entre os grupos. KHANDARE et al. (2005), analisando amostras sangüíneas de coelhos tratados com 150ppm de F na água de beber, observaram decréscimo do teor de $\mathrm{Cu}$. Ambos os elementos analisados ( $\mathrm{Cu}$ e $\mathrm{Zn}$ ) são essenciais para a formação da enzima antioxidante superóxido dismutase (SOD). A redução de um destes minerais pode reduzir a atividade da SOD (UNDERWOOD \& SUTTLE, 1999). No presente estudo, a redução na concentração de Cu seminal constatada nos animais tratados poderia induzir a uma menor atividade desta enzima. Contudo, isso não pôde ser avaliado devido à insuficiência de amostra.

Os resultados referentes a peso testicular e histomorfometria do testículo, cauda do epidídimo e canal deferente estão expressos na tabela 2. Quanto ao peso testicular, não houve diferença entre os grupos. Esse resultado corrobora o resultado obtido por BATAINEH \& NUSIER (2006), para os quais o peso testicular dos ratos não foi afetado pelo tratamento com 100 e 200ppm de NaF, durante 12 semanas. Contudo, aumento no peso testicular foi observado por GHOSH et al. (2002) em ratos tratados com NaF (20 $\mathrm{mg} \mathrm{kg}^{-1}$ de peso vivo por 29 dias). Esses autores sugeriram que esse incremento deve-se ao acúmulo de fluido no testículo, associado à dilatação dos túbulos seminíferos observada na avaliação histológica. DAS SARKAR et al. (2006), utilizando a mesma espécie, dose e tempo de tratamento, observaram aumento de $34 \%$ no peso testicular. Comparativamente a esses estudos que utilizaram outra espécie animal (ratos), no presente experimento, o peso testicular não foi alterado possivelmente porque os animais eram jovens e consumiram uma menor dose de F.

Quanto à histomorfometria dos testículos, não houve diferença no diâmetro dos túbulos seminíferos e na altura do epitélio basal entre os grupos. Essa diferença também não foi observada na altura do epitélio da cauda do epidídimo e do canal deferente. WAN et al. (2006) observaram diminuição no diâmetro dos túbulos seminíferos de ratos que receberam $\mathrm{NaF}$ (150 $\mathrm{m} \mathrm{L}^{-1}$ ) por 50, 100 e 120 dias. Além de uma dose mais elevada de $\mathrm{NaF}$ administrada em um período maior, os ovinos do presente experimento estavam em período pré-pubere e de puberdade inicial, sendo este um período mais suscetível aos efeitos do $\mathrm{NaF}$, diferentemente de outros estudos que utilizaram animais adultos. Este fato corrobora a possibilidade de uma maior resistência reprodutiva dos ovinos aos efeitos do NaF.

Neste estudo, no que se refere à histologia dos órgãos reprodutivos, não foram verificadas alterações referentes à integridade das estruturas analisadas em todos os animais. Observaram-se espermatozóides no lúmen dos túbulos seminíferos, na cauda do epidídimo e no canal deferente. CHINOY \& SEQUEIRA (1989) mencionaram que a administração

Tabela 2 - Média \pm desvio padrão do peso testicular e do diâmetro do túbulo seminífero e da altura do epitélio do testículo, do epidídimo e do canal deferente de ovinos alimentados com sal iodado (controle) acrescido de fluoreto de sódio (4,7 $\mathrm{mg} \mathrm{F} \mathrm{kg}^{-1}$ de peso vivo, tratado) durante 150 dias,.

\begin{tabular}{lcc}
\hline Parâmetro & Controle $(\mathrm{n}=6)$ & Tratado $(\mathrm{n}=6)$ \\
\hline Peso Testicular $(\mathrm{g})$ & $364 \pm 49,6$ & $376 \pm 108,7$ \\
Diâmetro túbulo seminífero $(\mu \mathrm{m})$ & $208,4 \pm 25,5$ & $195,9 \pm 5,8$ \\
Altura epitélio seminífero $(\mu \mathrm{m})$ & $65,0 \pm 1,2$ & $63,7 \pm 2,9$ \\
Altura epitélio epididimário $(\mu \mathrm{m})$ & $23 \pm 0,5$ & $24 \pm 0,5$ \\
Altura epitélio do canal deferente $(\mu \mathrm{m})$ & $26,1 \pm 8,3$ & $23,4 \pm 7,9$ \\
\hline
\end{tabular}


crônica de F (10 e 20mg NaF kg-1 de peso vivo, durante 30 dias) pode causar danos na histoarquitetura dos órgãos reprodutivos, como denudação e vacuolização das células. KOUR \& SINGH (1980), analisando a histologia testicular de ratos tratados com $\mathrm{NaF}$ na água de beber (500 e 1000ppm), durante três meses, verificaram alterações degenerativas nos túbulos seminíferos, como atrofia e necrose. Em coelhos também se observou atrofia e necrose dos túbulos seminíferos, utilizando doses de 10, 20 e 50 $\mathrm{mg} \mathrm{F} \mathrm{kg}^{-1}$ de peso vivo, durante 100 dias, além de deficiente diferenciação e maturação dos espermatócitos (SHASHI, 1990).

A absorção do $\mathrm{F}$ e os efeitos tóxicos exercidos sobre o sistema reprodutivo podem ser minimizados pela utilização de cálcio (CHINOY et al., 1995). Esse elemento se liga ao F e atua como antídoto, formando complexos insolúveis (EKAMBARAM \& PAUL, 2002; ZHOU et al., 2007). No estudo realizado por CHINOY et al. (1997) em ratos, foi efetuado inicialmente o tratamento com $\mathrm{NaF}\left(10 \mathrm{mg} \mathrm{kg}^{-1}\right.$ de peso corporal), durante 30 dias e, subseqüentemente, tratamento com fosfato de cálcio $\left(62,5 \mathrm{mg}\right.$ animal $\left.{ }^{-1} \mathrm{dia}^{-1}\right)$, durante o mesmo período. $\mathrm{O}$ resultado demonstrou que o cálcio exerce influência benéfica, restabelecendo a atividade de algumas enzimas específicas da cauda do epidídimo (adenosina trifosfatase e succinato dehidrogenase). No presente estudo, o cálcio não foi intencionalmente administrado aos animais. Porém, o feno de alfafa oferecido aos animais (3\% do peso vivo) revelou teores de $18,9 \mathrm{~g} \mathrm{~kg}^{-1}$ MS de cálcio. Assim, a quantidade de Ca diariamente consumida pelos animais era superior ao requerimento diário (2,4g kg-1 MS) para a espécie ovina (UNDERWOOD \& SUTTLE, 1999). Talvez essa seja uma hipótese para que os efeitos tóxicos do F sobre o sistema reprodutivo não tenham sido tão evidentes e intensos nesse estudo.

\section{CONCLUSÃO}

A administração crônica de flúor para ovinos jovens não afeta a capacidade reprodutiva de uma forma geral. Entretanto, os dados sugerem que o flúor pode reduzir a lipoperoxidação e os teores de cobre que são essenciais para a capacitação espermática e a fertilização.

\section{COMITÊ DE ÉTICA E BIOSSEGURANÇA}

A metodologia utilizada foi aprovada pela Comissão de Ética e Biossegurança da Universidade Federal de Santa Maria sob o parecer n⿳⺈ 49/2007 e os estudos com os animais foram realizados de acordo com normas éticas.

\section{REFERÊNCIAS}

AGARWAL, A.; PRABAKARAN, S.A. Oxidative stress and antioxidants in male infertility: a difficult balance. Iranian Journal of Reproductive Medicine, v.3, n.1, p.1-8, 2005.

BATAINEH, H.N.; NUSIER, M.K. Impact of 12-week ingestion of sodium fluoride on aggression, sexual behavior, and fertility in adult male rats. Fluoride, v.39, n.4, p.293301, 2006.

BHANUPRAKASH, G. Fluoride toxicity and oxidative stress. Fluoride, v.37, n.1, p.43-44, 2004.

CENESIZ, S. et al. Chronic effects of fluoride in Tuj sheep on serum levels of total protein, albumin, uric acid and nitric oxide and activities of lactate dehydrogenase and leucine aminopeptidase. Fluoride, v.38, n.1, p.52-56, 2005.

COLLINS, T.F.X. et al. Multigeneration evaluation of sodium fluoride in rats. Food Chemical Toxicology, v.39, n.6, p.601613, 2001

CHINOY, N.J.; SEQUEIRA, E. Effects of fluoride on the histoarchitecture of reproductive organs of the male mouse. Reproduction Toxicology, v.3, n.4, p.261-267, 1989.

CHINOY, N.J. et al. Amelioration of fluoride toxicity in some accessory reproductive glands and spermatozoa of rat. Fluoride, v.28, n.2, p.75-86, 1995.

CHINOY, N.J. et al. Fluoride toxicity on rat tests and cauda epididymal tissue components and its reversal. Fluoride, v.30, n.1, p.41-50, 1997.

CHLUBEK, D. Fluoride and oxidative stress. Fluoride, v.36, n.4, p.217-228, 2003.

DAS SARKAR, S. et al. Management of fluoride induced testicular disorders by calcium and vitamin-E co-administration in the albino rat. Reproductive Toxicology, v.22, n.4, p.606612, 2006.

DUNIPACE, A.J. et al. Genotoxic evaluation of chronic fluoride exposure: micronucleus and mouse sperm morphology studies. Journal Dental Research, v.68, n.1, p.1525-1528, 1989.

EATON A.D. et al. Standard methods for the examination of water an wastewater. Washington: American Public Health Association, 1995. 1018p.

EKAMBARAM, P.; PAUL, V. Modulation of fluoride toxicity in rats by calcium carbonate and by withdrawal of fluoride exposure. Pharmacology Toxicology, v.90, n.3, p.53-59, 2002.

ELLMAN, G.L. Tissue sulphydril groups. Archives Biochemistry Biophysical, v.82, n.1, p.70-77, 1959.

GHOSH, D. et al. Testicular toxicity in sodium fluoride treated rats: association with oxidative stress. Reproductive Toxicology, v.16, n.4, p.385-390, 2002.

HUANG, C. et al. Toxic effects of sodium fluoride on reproductive function in male mice. Fluoride, v.40, n.3, p.162168, 2007. 
KALYANALAKSHMI, P. et al. Lipid peroxidation and antioxidant enzyme status of adult males with skeletal fluorosis in Andhra Pradesh, India. Fluoride, v.40, n.1, p.42-45, 2007.

KESSABI, M. et al. Experimental fluorosis in sheep: alleviating effects of aluminum. Veterinary Human Toxicologic, v.28, n.4, p.300-304, 1986.

KHANDARE, A.L. et al. Beneficial effect of cooper supplementation on deposition of fluoride in bone in fluoride and molybdenum fed rabbits. Calcified Tissue International, v.77, n.4, p.233-238, 2005.

KOUR, K.; SINGH, J. Histological finding of mice testes following fluoride ingestion. Fluoride, v.13, n.4, p.160-162, 1980.

KRECHNIAK, J.; INKIELEWICZ, I. Correlations between fluoride concentrations and free radical parameters in soft tissues of rats. Fluoride, v.38; n.4, p.293-296, 2005.

LI, Y. et al. Effects of fluoride on the mouse sperm morphology test. Journal Dental Research, v.66, n.9, p.1509-1511, 1987.

MOURA, C.S. et al. Avaliação histomorfométrica do parênquima testicular de ratos adultos tratados com diferentes doses de ivermectina. Arquivo Brasileiro de Medicina Veterinária e Zootecnia, v.58, n.5, p.799-808, 2006.

OHKAWA, H. et al. Assay for lipid peroxides in animal tissues by thiobarbituric acid reaction. Analytical Biochemistry, v.95, n.2, p.351-358, 1979.

ORTIZ-PÉREZ, D. et al. Fluoride-induced disruption of reproductive hormones in men. Environmental Research, v.93, n.1, p.20-30, 2003.

PATEL, P.D.; CHINOY, N.J. Influence of fluoride on biological free radical reactions in ovary the mice and its reversal. Fluoride, v.31, n.3, p.27, 1998.

PUSHPALATHA, T. et al. Exposure to high fluoride concentration in drinking water will affect spermatogenesis and steroidogenesis in male albino rats. BioMetals, v.18, n.3, p.207-212, 2005.

RZEUSKI, R. et al. Interactions between fluoride and biological free radical reactions. Fluoride, v.31, n.1, p.43-45, 1998.

SHASHI, A. Histophatological changes in rabbit testes during experimental Fluorosis. Folia Morphologica, v.38, n.1, p.6365, 1990.

SHIVARAJASHANKARA, Y.M. et al. Effect of fluoride intoxication on lipid peroxidation and antioxidant systems in rats. Fluoride, v.34, n.2, p.108-113, 2001.

SILVA, A.E.D.F. et al. Capacidade reprodutiva de touros de corte: funções, anormalidades e fatores que a influenciam. Campo Grande: Embrapa/CNPGC, 1993. 128p.

SPRANDO, R.L. et al. Testing the potential of sodium fluoride to affect spermatogenesis in the rat. Food Chemical Toxicology, v.35, n.9, p.881-890, 1997.

SUSHEELA, A.K.; KUMAR, A. A study of the effect of high concentrations of fluoride on the reproductive organs of male rabbits, using light and scanning electron microscopy. Journal Reproductive Fertility, v.92, n.2, p.353-360, 1991.

UNDERWOOD, E.J.; SUTTLE, N.F. The mineral nutrition of livestock. 3.ed. London: CAB International, 1999. 664p.

WAN, S. et al. Effects of high fluoride on sperm quality and testicular histology in male rats. Fluoride, v.39, n.1, p.17-21, 2006.

ZAKRZEWSKA, $\mathrm{H}$. et al. In vitro influence of sodium fluoride on ram semen quality and enzyme activities. Fluoride, v.35, n.3, p.153-160, 2002.

ZAYAS, L.E.S et al. Papel del estrés oxidativo en la infertilidad masculina. Revista Cubana Investigación Biomédica, v.19, n.3, p.202-205, 2000.

ZHOU, B. et al. Effects of malnutrition and supplemented nutrition on nonspecific immune function changes induced by fluoride in rabbits. Fluoride, v.40, n.3, p.169-177, 2007. 